\title{
Normal Laboratory Test Result
}

National Cancer Institute

\section{Source}

National Cancer Institute. Normal Laboratory Test Result. NCI Thesaurus. Code C35766.

A laboratory test result indicating the results of the lab test are within normal parameters for the age and population. 